\title{
Reduction/adsorption of $\mathrm{Cr}(\mathrm{VI})$ in aqueous solution using modified plum kernel shell with tartaric acid
}

\begin{abstract}
This work investigates the adsorption of chromium ions, $\mathrm{Cr}(\mathrm{VI})$ on modified plum kernel shell with tartaric acid (MPKS). For adsorption studies, different parameters were optimized such as $\mathrm{pH}$, MPKS dosage, and contact time through batch technique. Equilibrium models such as Langmuir, Freundlich and Dubinin-Radushkevich (D-R) were used to determine the isotherm parameters associated with the adsorption process. Maximum adsorption capacities of $\mathrm{Cr}(\mathrm{VI})$ were $181.8 \mathrm{mg} / \mathrm{g}$.
\end{abstract}

Keywords: plum, shell, adsorption, isotherm
Volume 6 Issue 2 - 2017

Șerife Parlayici, Erol Pehlivan

Department of Chemical Engineering, Selcuk University, Turkey

Correspondence: Erol Pehlivan, Department of Chemical Engineering, Selcuk University, Campus, 42079 Konya, Turkey, Email erolpehlivan@gmail.com

Received: August 26, 2017 | Published: October 10, 2017
Abbreviations: MPKS, modified plum kernel shell; PKS, plum kernel shell; $\mathrm{HCl}$, hydrochoride; $\mathrm{NaOH}$, sodium hydroxide

\section{Introduction}

Water pollution is one of the most important issues to be guided in the context of emerging environmental problems. Water pollution is caused by toxic metals from industrial applications. ${ }^{1}$ Toxic metals can seriously harm to human health, even at low concentrations in the water, resulting in serious health problems, even death. Chromium ions are the most hazardous toxic metals. Chromium has become a serious health concern due to its release into the environment. ${ }^{2}$ The most common methods for removing heavy metal ions from water are: chemical precipitation, membrane filtration, ion exchange, reverses osmosis and adsorption..$^{3-5}$ Among all techniques, adsorption with MPKS is a green separation process. The application is easy; the purification is effective and cheap.

During selection of adsorbent; attention should be paid to features such as high adsorption capacity, low cost, high adsorption rate and reusability. Suitable adsorbent material for removing $\mathrm{Cr}(\mathrm{VI})$ due to their content is plum kernel shell (PKS) and it contains lignin and carbohydrate (cellulose and hemicelluloses). This adsorbent has cellulose and lignin which contain different polar functional groups, such as alcohols, aldehydes, ketones, acids, phenolic hydroxides, and ethers which may be involved in the surface application. The modification of PKS by tartaric acid was subsequently investigated for the potential adsorbent for the removal of $\mathrm{Cr}(\mathrm{VI})$ from aqueous solutions. Effective parameters such as initial $\mathrm{pH}$, initial metal concentration, contact time, and adsorbent dosage related to adsorption were investigated.

\section{Materials and methods}

PKS was obtained from Konya-Turkey. It was cleaned, dried in sunlight ground to pass through a $125 \mu \mathrm{m}$ sieve. Then PKS was treated with $1.2 \mathrm{M}$ tartaric acid at $80^{\circ} \mathrm{C}$ for $8 \mathrm{~h}$ and labeled as MPKS. MPKS was then washed to neutral $\mathrm{pH}$ and dried at $50^{\circ} \mathrm{C}$ for $24 \mathrm{~h}$. All other chemicals were purchased from Merck Company. All chemicals used in the experiments were in analytic grade and ultrapure water was used to prepare required solutions. The $\mathrm{pH}$ of the solution was adjusted by mixing the appropriate amount of $0.1 \mathrm{M}(\mathrm{HCl} / \mathrm{NaOH})$. A stock solution of $\mathrm{Cr}(\mathrm{VI})$ with a concentration of $1000 \mathrm{ppm}$ was prepared by dissolving $\mathrm{K} 2 \mathrm{Cr} 2 \mathrm{O} 7$ in distilled water. The residual solution was investigated by a UV-vis Spectrophotometer (Schmadzu UV-1700)
( $\lambda: 540 \mathrm{~nm}$ ) using a diphenylcarbazide reagent for determination of $\mathrm{Cr}(\mathrm{VI})$. For all parameters $(\mathrm{pH}$, metal concentration, adsorbent dose and contact time), each experimental steps was replicated three times and avarage value was recorded.

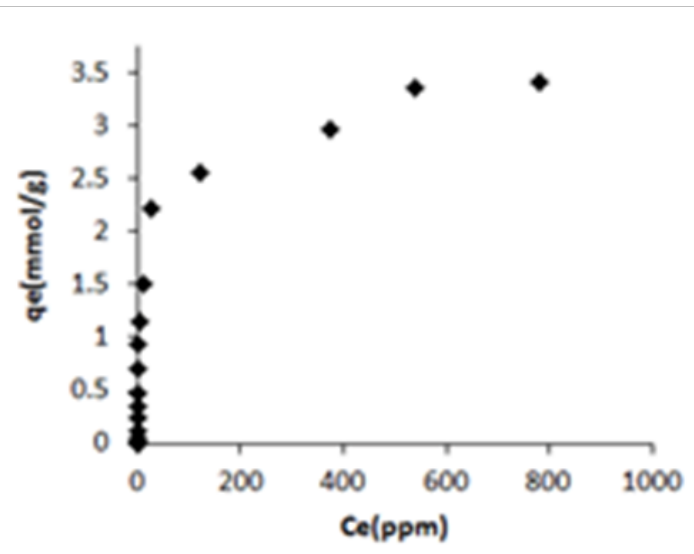

Figure I Equilibrium adsorption isotherm of $\mathrm{Cr}(\mathrm{VI})$ ions on MPKS.

\section{Results and discussion}

The contact time for taking $\mathrm{Cr}(\mathrm{VI})$ ions with MPKS was ranged from 5 to 360 minutes. The agitation time showed fast $\mathrm{Cr}(\mathrm{VI})$ adsorption during the first 5-30min of agitation period and then reached to the equilibrium at the end of $60 \mathrm{~min}$ of contact period. The initial rapid removal could be due to high initial $\mathrm{Cr}(\mathrm{VI})$ concentrations and free $\mathrm{Cr}(\mathrm{VI})$ binding sites at the functional groups of MPKS. All conditions for the $\mathrm{Cr}(\mathrm{VI})$ adsorption were kept constant and only MPKS dosage $(1,2,4,6,8,10 \mathrm{mg} / \mathrm{L})$ was changed for a series of experiments. When the amount of MPKS increased ( $1 \mathrm{~g} / \mathrm{L}$ from $4 \mathrm{~g} / \mathrm{L}$ ) the ability to capture $\mathrm{Cr}(\mathrm{VI})$ increased, but after increasing the amount of adsorbent, it was marginally reduced and the adsorption increased. With increase in the residence time, the adsorption was increased to a constant value. For this reason, the adsorbent dosage for $\mathrm{Cr}(\mathrm{VI})$ was taken as $4 \mathrm{~g} / \mathrm{L}$ in the experiments. The $\mathrm{pH}$ of the solution plays an important role in adsorption mechanism of $\mathrm{Cr}(\mathrm{VI})$ ions. The experiments were carried out at a $\mathrm{pH}$ range 1.5-6. The hydrolysis of solution, the $\mathrm{pH}$ of the solution, the redox reactions in the solution phase, the coordination groups on the surface of MPKS, and the ionic state can affect $\mathrm{Cr}(\mathrm{VI})$ removal. The adsorption capacity of MPKS is $\mathrm{pH}$ dependent and the maximum adsorption took place at $\mathrm{pH} 2$. 
Table I Adsorption Isotherm Constants for $\mathrm{Cr}(\mathrm{VI})$

\begin{tabular}{|c|c|c|c|c|c|c|c|c|c|c|}
\hline \multicolumn{4}{|c|}{ Langmuir Isotherm } & \multicolumn{3}{|c|}{ Freundlich Isotherm } & \multicolumn{4}{|c|}{ D-R Isotherm } \\
\hline $\mathbf{Q}_{\mathrm{m}}$ & b & $\mathbf{R}^{2}$ & $\mathbf{R}_{\mathrm{L}}$ & $\mathbf{K}_{\mathrm{f}}$ & $\mathbf{n}$ & $\mathbf{R}^{2}$ & $\mathbf{X}_{\mathrm{m}}$ & $\mathbf{K}$ & E & $\mathbf{R}^{2}$ \\
\hline 181.8 & 0.029 & 0.988 & 0.25 & 11.03 & 2.09 & 0.646 & 0.0099 & 0.0042 & 10.91 & 0.726 \\
\hline
\end{tabular}

Adsorption studies of $\mathrm{Cr}(\mathrm{VI})$ at different concentrations in the range of 5-1500ppm ( $4 \mathrm{~g} / \mathrm{L}$ adsorbent) were shown by Freundlich, Langmuir, D-R Isotherm. Freundlich, Langmuir and D-R isotherms (Figure 1). Freundlich, Langmuir and D-R adsorption isotherms parameter were given in Table 1. $K_{f}$ and $\mathrm{n}$ constant values were calculated to define the equilibrium fit Freundlich equation. $\mathrm{n}$ values were determined as 2.09. If this value is between 1 and 10 , Freundlich isotherm can be selected for adsorption. From Dubinin-Radushkevich (D-R) isotherm, $X_{m}, \mathrm{~K}$ and $\mathrm{E}$ values were calculated. The adsorption energy $(E \mathrm{ad})$ was calculated to be $10.91 \mathrm{~kJ} / \mathrm{mol}$. The fitness of adsorption can be compared according to $R_{L}$ value. If $R_{L}$ is between 0 and 1 , it specifies the relevance of Langmuir adsorption isotherm. ${ }^{6,7} \mathrm{R}_{\mathrm{L}}$ values of $\mathrm{Cr}(\mathrm{VI})$ are 0.25 . According to Langmuir isotherm, the maximum capacity $\left(\mathrm{q}_{\mathrm{m}}\right)$ is $181.8 \mathrm{mg} / \mathrm{g}$.

\section{Conclusion}

The adsorption behavior of $\mathrm{Cr}(\mathrm{VI})$ was investigated in the batch experiments. Adsorption was found to depend on $\mathrm{pH}$, adsorbent dose and contact time. The maximum adsorption for $\mathrm{Cr}(\mathrm{VI})$ was at $\mathrm{pH}$ 2.0. The MPKS attained equilibrium in $60 \mathrm{~min}$. Adsorption of $\mathrm{Cr}(\mathrm{VI})$ obeys Langmuir equation. Using the Langmuir model equation, the maximum capacities of MPKS for $\mathrm{Cr}(\mathrm{VI})$ was found to be $181.8 \mathrm{mg} / \mathrm{g}$. PKS can easily found in Turkey and it is expected that modified PKS will be economical to remove $\mathrm{Cr}(\mathrm{VI})$ from wastewater plants.

\section{Conflicts of interest}

None.

\section{Acknowledgements}

None.

\section{References}

1. Shen F, Su J, Zhang X, et al. Chitosan-derived carbonaceous material for highly efficient adsorption of chromium (VI) from aqueous solution. Int J Biol Macromol. 2006;91:443-449.

2. Romero-Gonzalez J, Peralta-Videa JR, Rodriguez E, et al. Determination of thermodynamic parameters of $\mathrm{Cr}(\mathrm{VI})$ adsorption from aqueous solution onto Agave lechuguilla biomass. The Journal of Chemical Thermodynamics. 2005;37(4):343-347.

3. Parlayıcı S, Yar A, Avc1 A, et al. Removal of hexavalent chromium using polyacrylonitrile/titanium dioxide nanofiber membrane. Journal of Desalination and Water Treatment. 2016;57(34):16177-16183.

4. Sekhar KC, Kamala CT, Chary NS, et al. Removal of heavy metals using a plant biomass with reference to environmental control. International Journal of Mineral Processing. 2003;68(1):37-45.

5. Wang YY, Lu HH, Liu YX, et al. Ammonium citrate-modified biochar: An adsorbent for $\mathrm{La}$ (III) ions from aqueous solution. Colloids and Surfaces A: Physicochemical and Engineering Aspects. 2016;509:550-563.

6. Parlayıc1 S, Pehlivan E. Natural biosorbents (garlic stem and horse chesnut shell) for removal of chromium(VI) from aqueous solutions. Environmental Monitoring and Assessment. 2015;187:763.

7. Parlayıcı S, Karakuzu K, Baybara AS, et al. Utilizatio2017;n of eco-friendly gelatin for $\mathrm{Cr}(\mathrm{VI})$ adsorption. Desalination and Water Treatment. 73:308-315. 